\title{
ASPECTOS PROBLEMÁTICOS DE LA DECLARACIÓN DEL IMPUTADO DURANTE EL PROCESO PENAL
}

\section{PROBLEMATIC ASPECTS OF THE DECLARATION OF THE DEFENDANT DURING THE CRIMINAL PROCEDURE}

\author{
Renzo Espinoza Bonifaz \\ Docente \\ Universidad de San Martín de Porres \\ aespinozab@usmp.pe \\ Perú, Lima
}

\section{SUMARIO}

- Introducción.

- Garantías durante la declaración del imputado.

- La declaración del acusado en juzgamiento.

- Lectura de las declaraciones previas del acusado durante el juzgamiento.

- Aptitud probatoria de la declaración del acusado.

- Conclusiones.

\section{RESUMEN}

El artículo de investigación describe y precisa las garantías que deben de observarse de manera irrestricta durante en la declaración del imputado durante la etapa de investigación preparatoria, y la de juzgamiento. Asimismo, busca establecer si la lectura de las declaraciones previas del imputado durante el juzgamiento afecta su derecho a guardar silencio. De igual manera, intenta precisar cómo se deben valorar las declaraciones contradictorias del imputado durante el proceso penal. Finalmente, persigue determinar si la declaración que brinda el acusado durante el proceso penal tiene aptitud probatoria para ser valorada por el órgano jurisdiccional.

\section{ABSTRACT}

The research article describes and specifies the guarantees that must be observed in an unrestricted manner during the declaration of the accused during the preparatory investigation stage, and the trial. It also seeks to establish whether the reading of the previous statements of the accused during the trial affects their right to remain silent. In the same way, it tries to specify how the contradictory statements of the accused should be evaluated during the criminal process. Finally, it seeks to determine whether the statement provided by the accused during the criminal process has evidentiary aptitude to be assessed by the jurisdictional body.

\section{PALABRAS CLAVES}

Proceso penal; declaración del imputado; valor probatorio; garantías procesales; estado de inocencia.

\section{KEYWORDS}

Criminal process, declaration of the accused, probative value, procedural guarantees, innocence status.

\section{INTRODUCCIÓN}

Normativamente, la declaración del imputado se encuentra regulada del artículo 86 al 89 del Código Procesal Penal, dichas disposiciones legales se encuentran en el Capítulo III del Título II (El imputado y el abogado defensor) de la Sección IV (El Ministerio Publico y los demás sujetos procesales) del Libro Primero (Disposiciones Generales). Asimismo, el literal a) del numeral 3 del artículo 337, que se encuentra en el Título III (La Investigación Preparatoria) de la Sección I (La Investigación Preparatoria) del Libro Tercero (Proceso 
Común), establece que el Fiscal puede disponer la concurrencia del imputado para informar sobre circunstancias útiles para los fines de la investigación, prescribiendo que se encuentra obligado a comparecer ante la Fiscalía, y a manifestarse sobre los hechos objeto de investigación, agregando que su inasistencia injustificada determinará su conducción compulsiva.

Por otro lado, los artículos 376 y 377, que se encuentran en el Título IV (La actuación probatoria) de la Sección III (El juzgamiento) del Libro Tercero (Proceso Común), establecen las reglas del examen del acusado durante el juicio oral, estableciendo la forma en que declara, su finalidad, el tipo de preguntas permitidas, el orden de su interrogatorio, el poder de dirección y control que tiene el Juez sobre las preguntas realizadas, y la manera en que se realizará el examen si son varios acusados.

De esta manera, podemos apuntar tres tipos de manifestaciones que el imputado puede brindar durante el proceso penal: declaración indagatoria, declaración del imputado y examen del acusado. Teniendo en consideración, además, que si admite libre, sincera y espontáneamente la imputación formulada en su contra ante el juez o el fiscal en presencia de su abogado defensor, y esta declaración puede corroborarse debidamente por otro u otros elementos de convicción nos encontraríamos ante una confesión.

No esta demás precisar que la declaración del imputado es por sobre todo un medio de defensa de fondo, es decir, es la principal herramienta procesal que tiene para contradecir los cargos formulados en su contra, haciendo efectiva la garantía procesal del derecho de defensa consagrada en el numeral 14 del artículo 139 de la Constitución Política del Estado. Por lo tanto, su empleo es irrestricto, permitiéndosele que la realice cuando aprecie conveniente, las veces que considere necesarias para ampliar su defensa, con la única limitación de que no sea utilizada maliciosa o dilatoriamente por el imputado. Por ello, la declaración del imputado constituye la máxima representación de su defensa material durante el proceso penal, en consecuencia, debe actuarse respetando todas las garantías constitucionales y legales establecidas en el ordenamiento jurídico procesal a su favor.
En este orden de ideas, los objetivos del presente artículo de investigación son: 1) establecer si la lectura de las declaraciones previas del imputado durante el juzgamiento afecta su derecho a guardar silencio, 2) precisar cómo se deben valorar las declaraciones contradictorias del imputado durante el proceso penal, y 3) determinar si la declaración del acusado tiene aptitud probatoria.

\section{GARANTÍAS DURANTE LA DECLARACIÓN DEL IMPUTADO}

La ley procesal penal, es decir, el Código Procesal Penal establece claramente las garantías y reglas procesales para que el imputado brinde su declaración durante la primera etapa del proceso penal, la Investigación Preparatoria. Lo primero que se establece es la presencia obligatoria de su abogado defensor, lo cual guarda coherencia con lo establecido por el numeral $14 \mathrm{del}$ artículo 139 de la Constitución Política del Estado que establece que toda persona: "Tiene derecho a comunicarse personalmente con un defensor de su elección y a ser asesorada por éste desde que es citada o detenida por cualquier autoridad".

A diferencia de la defensa material, que el imputado ejerce directamente, el abogado defensor desarrolla una defensa técnica, ya que al ser un profesional dotado de conocimientos jurídicos le es posible brindar un asesoramiento basado en criterios interpretativos de la ley penal, así en caso de duda o desconocimiento de algún tema legal por parte del imputado lo puede ilustrar de una mejor manera, asimismo, el abogado defensor se encuentra facultado para interrogar directamente a su defendido, $\mathrm{y}$ ofrecer los medios de investigación y de prueba que estime pertinentes.

El artículo 87 del Código Procesal Penal establece las instrucciones preliminares que deben de informársele al imputado antes de iniciar con su interrogatorio. Lo primero constituye el acto de intimación, es decir, la comunicación detallada de los hechos delictivos que se le imputan, las disposiciones legales aplicables, así como los elementos de convicción que ya se hayan obtenido hasta ese momento. Luego de ello, se le debe de instruir sobre los principios y garantías constitucionales que le asisten, es decir, el 
derecho a guardar silencio, a ser asistido por un abogado defensor de manera gratuita, a ofrecer actos de investigación.

Posteriormente, el fiscal o el juez exhortará al imputado a que responda con claridad y precisión las preguntas que se le formulen, esto no quiere decir, que se encuentra obligado a responderlas, a decir la verdad, o auto incriminarse. Lo que si pueden hacer es informarle sobre los beneficios legales que podría obtener si coopera al pronto esclarecimiento de los hechos delictuosos, ya sea confesando o colaborando de manera eficaz para desarticular una organización criminal.

Cabe resaltar que el imputado debe declarar sin ataduras físicas, es decir, sin grilletes $u$ otro elemento de seguridad que lo constriña, y solo en presencia de quienes estén autorizados legalmente para asistir a la diligencia. Asimismo, debe constatarse que se encuentre bien de salud física y mental para poder iniciar su declaración, pues la misma requiere de que el imputado este apto para poder expresarse consciente y voluntariamente.

Como puede observarse en la normativa procesal pertinente, la estructura de la declaración del imputado propiamente dicha tiene tres fases. En la primera se buscar identificar correctamente al imputado, para ello se le pregunta sobre sus datos personales, asimismo, se busca conocer si tiene antecedentes procesales, bienes patrimoniales, y la relación existente con el agraviado, y con otros procesados, si los hubiera. En la segunda se le permite al imputado declarar libremente sobre los hechos objeto de imputación, y ofrecer si considera oportunos actos de investigación o de prueba.

La tercera fase consiste en el interrogatorio por parte del fiscal y el abogado defensor. Las preguntas realizadas deben ser pertinentes, claras y precisas. Están terminantemente prohibidas las preguntas ambiguas, capciosas, sugestivas, y coactivas. También se le podrá pedir al imputado que reconozca documentos, personas, voces, sonidos, o cosas durante el interrogatorio.

Se debe respetar de manera exacta las palabras expresadas por el imputado durante su interrogatorio, por ende, el acta que contiene su trascripción las reproducirá de la manera más fiel posible, para ello el imputado podrá dictar sus respuestas. Antes de firmar el acta de la declaración se le debe permitir al imputado leerla. Si se niega a firmarla se señalará el motivo.

\section{LA DECLARACIÓN DEL ACUSADO EN JUZGAMIENTO}

La manifestación del acusado durante el juzgamiento es inevitable, es más, resulta ser la primera actuación de la fase probatoria del juicio oral, lo cual desde nuestro punto de vista, colisiona con la idea del litigio penal estratégico promovido por el sistema procesal acusatorio moderno, pues, al ordenar legislativamente el debate probatorio se afecta la posibilidad de que las partes puedan plantear estratégicamente su teoría del caso ante el órgano jurisdiccional, debilitando con ello la libertad de ordenar y manejar los medios de prueba disponibles para convencer al juez de que nuestra versión de cómo sucedieron los hechos materia de imputación es la verdadera. Además, resulta incomprensible que la actividad probatoria se inicie con el contrainterrogatorio del órgano de prueba más hostil para la fiscalía, el acusado.

No obstante, antes de iniciar con el interrogatorio del acusado, durante la etapa de instalación de la audiencia, con exactitud, luego de los alegatos preliminares, es deber del juez informar al acusado sobre sus derechos precisándole que es totalmente libre de manifestarse sobre la acusación en su contra o de abstenerse de declarar, haciendo uso de su derecho a guardar silencio. Cabe resaltar, que el acusado tiene la libertad de solicitar en cualquier momento del juicio ser escuchado, para ampliar, aclarar o complementar su declaración, o para hacerlo si antes hubiera optado por negarse a declarar. De igual manera, en todo instante, salvo cuando esté siendo interrogado, podrá hacer consultas a su abogado.

Luego de haber sido instruido en sus derechos, el juez le pregunta al acusado si se declara culpable o no de los hechos delictivos que le atribuye el fiscal en su acusación, si el acusado acepta los cargos en su contra, previa consulta con su abogado defensor, el juez declara la conclusión del juicio oral dictándose la sentencia conformada respectiva. En caso no se declare no culpable, se procederá a su interrogatorio en la fase respectiva. 
Durante su declaración el acusado responderá oral y libremente sobre lo que se le pregunte, el propósito de su interrogatorio es que pueda brindar las explicaciones y aclaraciones sobre los hechos por los cuales se le juzga, para ello, resulta obligatorio que las preguntas formuladas sean pertinentes, directas, claras y útiles, en consecuencia, están prohibidas las preguntas repetitivas, capciosas, ambiguas, y sugestivas. No obstante, consideramos que dado que el acusado es un órgano de prueba hostil para el fiscal, sólo en su caso están permitidas las preguntas sugestivas.

Es importante que el juez ejerza cabalmente su poderde direccióny control durante la audiencia, declarando de oficio, o a pedido de parte, la inadmisibilidad de las preguntas prohibidas. El primero en interrogar será el fiscal, luego el abogado del actor civil, a continuación, el del tercero civil, posteriormente el de la persona jurídica, y finalmente su abogado defensor. El juez excepcionalmente podrá preguntar solo cuando hubiera quedado algún vacío en una línea de interrogatorio formulada por alguna de las partes, es decir, sus preguntas serán únicamente aclaratorias.

\section{LECTURA DE LAS DECLARACIONES PREVIAS DEL ACUSADO DURANTE EL JUZGAMIENTO}

La ley procesal penal establece en el artículo 376 que, si el acusado se niega a declarar parcial o totalmente, haciendo uso de su derecho a guardar silencio, el juez le advertirá que el juzgamiento continuará sin su declaración, y ordenará que se lean sus declaraciones previas al juzgamiento, es decir, las declaraciones que brindó ante el fiscal durante la investigación preparatoria. El silencio del imputado conforma el contenido esencial del derecho de defensa, el derecho a no auto incriminarse, el cual no debe producirle perjuicio alguno, es decir, no puede valorarse negativamente que el imputado se haya negado a brindar su declaración, lo cual también significaría una vulneración a su estado de inocencia. Por ende,

No obstante, consideramos que la disposición legal citada en el párrafo anterior no vulnera de forma alguna su derecho a guardar silencio Ello resulta así, en el entendido de que las declaraciones que el acusado brindó durante la investigación preparatoria ante el fiscal, han sido llevadas a cabo con todas las garantías establecidas por la Constitución Política y el Código Procesal Penal, las cuales han sido detalladas líneas arribas. En ese sentido, para revestir a las declaraciones previas de los pilares fundamentales en los que se inspira el juzgamiento, es decir, de los principios de contradicción, publicidad e inmediación, luego de ser leídas se le debe conceder al acusado la palabra para que, si lo desea, explique, aclare, refute o se pronuncie sobre su contenido.

Se debe tener muy en claro que las declaraciones previas del acusado no son medios de prueba documental, por lo que no resulta suficiente tan sólo su lectura, para que éstas declaraciones brindadas en sede de investigación preparatoria puedan ser utilizadas se debe de haber concedido al acusado alegar durante el juicio oral lo que estime conveniente respecto a ellas, lo cual permite plasmar de forma efectiva su derecho de contradicción o de defensa material, y además, le permite al juez percibir de manera directa y oral lo manifestado por el acusado, por tanto, se trata de un acto de prueba susceptible de ser valorado, ya que se produjo dentro del juicio respetando las garantías del debido proceso.

Además, el hecho de que el acusado no quiera declarar no causa que sus declaraciones previas sean inexistentes, el derecho a guardar silencio no tiene efectos retroactivos sobre las manifestaciones ya brindadas, es decir, no genera su extinción o cancelación. La única manera de que una declaración previa pueda ser excluida probatoriamente es si la misma ha sido obtenida, directa o indirectamente, vulnerando el contenido esencial de un derecho fundamental del imputado, pues sería ilegítima.

Por otro lado, si lo que está declarando el acusado en juzgamiento resulta contradictorio objetivamente con lo que manifestó en la etapa de investigación preparatoria, el cambio de versión del acusado requiere un tratamiento especial, por ello, al detectarse este acontecimiento se le debe leer su declaración previa, y preguntarle por qué razón ha variado su manifestación inicial, ello con el propósito de que el juzgador pueda percibir de manera inmediata sus explicaciones.

Sin lugar a dudas, resulta un trabajo racionalmente arduo para el juzgador elegir a cuál declaración otorgarle mérito probatorio. 
Ello es así porque toda declaración es eminentemente subjetiva, por tanto, debe preferir a la que esté mejor corroborada por indicios periféricos de carácter objetivo. Asimismo, el juez debe tener en cuenta que, si escoge la declaración brindada en la investigación preparatoria, al faltarle inmediación, ésta debe estar acreditada de una mejor manera. Además, el juez al emitir sentencia tiene que señalar de forma especial las razones por las cuales eligió esa declaración y no la otra.

En esa línea de ideas, el fundamento 5 de la Sentencia expedida por la Sala Penal Permanente de la Corte Suprema de Justicia de la Republica, Recurso de Nulidad N 30442004-Lima, señala:

Que, por lo demás, es de dejar sentado como doctrina general que cuando se trata de testigos o imputados que han declarado indistintamente en ambas etapas del proceso penal, en la medida en que la declaración prestada en la etapa de instrucción se haya actuado con las garantías legalmente exigibles -situación que se extiende a las declaraciones en sede policial, siempre que se cumpla lo expresamente estatuido en la norma habilitante pertinente referido a la presencia del Fiscal y, en su caso, del abogado defensor-, el Tribunal no está obligado a creer aquello que se dijo en el acto oral, sino que tiene libertad para conceder mayor o menor fiabilidad a unas $\mathrm{u}$ otras de tales declaraciones, pues puede ocurrir, por determinadas razones -que el Tribunal debe precisar cumplidamente-, que ofrezca mayor credibilidad lo declarado en la etapa de instrucción que lo dicho después en el juicio oral, en tanto dicha declaración se haya sometido al acto de contradicción con las de igualdad, publicidad e inmediación y trasunta una mayor verosimilitud $y$ fidelidad -cumplimiento, en su esencia, de los requisitos de legalidad y contradicción-.

En sentido contrario, el Pleno Jurisdiccional Distrital Penal de la Corte Superior de Justicia de Arequipa del año 2018, llevado a cabo el 23 de noviembre de 2018 , adoptó por mayoría que:

No está permitido el uso de la declaración previa del imputado para evidenciar contradicciones en su versión, porque: i) la declaración del acusado es un acto defensivo, no un medio de prueba; ii) la regulación normativa de la declaración del imputado es distinta a la declaración del testigo; iii) el uso de la declaración previa está regulada solo para peritos y testigos, más no para el imputado.

\section{APTITUD PROBATORIA DE LA DECLARACIÓN DEL ACUSADO}

Como señala Ferrajoli (1995):

En el interrogatorio del imputado es donde se manifiestan y se miden las diferencias más profundas entre método inquisitivo y método acusatorio. En el proceso inquisitivo pre moderno el interrogatorio del imputado representaba "el comienzo de la guerra forense", es decir, el primer ataque del fiscal contra el reo para obtener de él, por cualquier medio, la confesión (página 607).

Agrega:

Por el contrario, en el modelo garantista del proceso acusatorio, informado por la presunción de inocencia, el interrogatorio es el principal medio de defensa y tiene la única función de dar materialmente vida al juicio contradictorio y permitir al imputado refutar la acusación o aducir argumentos para justificarse (página 608).

Es por ello, que la doctrina mayoritaria identifica a la declaración del acusado como el principal medio de defensa de fondo con el que cuenta para contradecir la imputación esgrimida por el fiscal en su contra, y exponer su posición sobre cómo sucedieron los hechos. Sin dudas, la declaración del acusado es un acto complejo de aportación fáctica que preeminentemente tiene una función defensiva, no obstante, ello no impide que le pueda servir al juez para formarse convicción sobre la veracidad de los hechos imputados en el requerimiento acusatorio al contener información contrastable con otros medios de prueba.

Nuestro Código Procesal Penal no considera como medio de prueba a la declaración del acusado, lo que si hace con la confesión en su artículo 160. Es más, el artículo 375.1, 
referido al orden del debate probatorio, cuida en distinguir el examen del acusado de la actuación de los medios de prueba admitidos, pudiéndose inferir del dispositivo legal citado que la declaración del acusado no es un medio probatorio. Sin embargo, creemos que pese a lo señalado normativamente, la declaración del acusado sí tiene aptitud probatoria, lo que no quiere decir que por ello deje de ser su principal medio de defensa.

Sibien la declaración del acusado es considerada como un medio de defensa ello no imposibilita que se le pueda conceder aptitud probatoria. $\mathrm{Su}$ actuación tiene la finalidad de acreditar la versión defensiva del acusado sobre los hechos, por ende, si no se le concediera valor probatorio alguno, en realidad, no serviría para nada, su actuación seria totalmente en vano. De esta manera, resulta evidente que la versión de los hechos que ofrece el acusado constituye un dato que el juzgador debe tener en cuenta para ser valorado en conjunto con los otros medios de prueba actuados durante el juzgamiento.

Por otro lado, si bien consideramos que la declaración del acusado tiene aptitud probatoria, ello no significa que la misma pueda ser utilizada en su contra ante la ausencia de suficiencia probatoria. Es decir, las contradicciones, incoherencias o inconsistencias que pudieran percibirse de la declaración del acusado no pueden sustituir la ausencia de pruebas de cargo. No se puede condenar al acusado por no haber probado su coartada o versión de los hechos sino sólo ante la existencia de pruebas suficientes que desvirtúen, más allá de toda duda razonable, su estado de inocencia.

Por ello, es correcto lo afirmado por Ferrajoli (1995) cuando precisa que:

La verdad perseguida por el modelo acusatorio, concebida como relativa $o$ formal, se adquiere, como en cualquier investigación empírica, a través del procedimiento por ensayo y error. La principal garantía de su obtención se confía a la máxima exposición de las hipótesis acusatorias a la refutación de la defensa, es decir, al libre desarrollo del conflicto entre las dos partes del proceso, portadoras de puntos de vista contrastantes, precisamente porque son titulares de intereses opuestos.
En este sentido, se debe tener en cuenta lo señalado en el fundamento 3.7 de la Sentencia expedida por la Sala Penal Permanente de la Corte Suprema de Justicia de la Republica, Recurso de Nulidad $N^{\circ}$ 2467-2017-Tacna:

La declaración preliminar del imputado en la que reconocería la intencionalidad de agresión sexual a la agraviada no pude ser empleada como medio de prueba de cargo, dado que la versión del propio imputado no puede ser medio empleado en su perjuicio, en virtud del principio de no autoincriminación, siempre que no obren medios probatorios que corroboren la imputación fiscal (página 6).

De igual manera, es relevante lo señalado en el fundamento 4.4 de la Sentencia expedida por la Tercera Sala Penal de Apelaciones de la Corte Superior de Justicia de Arequipa, expediente $\mathrm{N}^{\circ}$ 92-2017:

Es doctrina aceptada mayoritariamente que la declaración del imputado es un medio de defensa, y no uno de investigación o de prueba, en efecto, la declaración del imputado perfecciona el contradictorio procesal, por tanto, configura el proceso mismo. De esta forma la declaración del imputado no puede ser considerada información probatoria, peor aún, en contra de los intereses del imputado. En todo caso la "mala justificación" sólo puede ser considerada un indicio posterior, si tiene la idoneidad razonable para engarzarse con otros indicios adicionales. La valoración de la declaración del imputado como fuente de información, revela en el fondo la pretensión de considerar al propio imputado como fuente de información idónea de cargo para su propia responsabilidad (página 4).

En sentido contrario, el fundamento 3.3 de la Sentencia expedida por la Tercera Sala Penal de Apelaciones de la Corte Superior de Justicia de Arequipa, expediente $\mathrm{N}^{\circ}$ 2324-2015 señala:

3.3.1. Debe tenerse presente que en el modelo inquisitivo, la declaración del imputado fue considerado como objeto, centralmente como objeto de prueba, de tal manera que era la principal fuente de información para probar el hecho punible imputado. Sin embargo, en el 
modelo procesal acusatorio el imputado es considerado como parte procesal (sujeto procesal $)^{1}$; por consiguiente la declaración del imputado es una expresión de voluntad contraria a la pretensión penal, la resiste; en efecto, la pretensión penal y la oposición deben generar un contradictorio coherente internamente que constituye el núcleo procesal. En ese orden, la declaración del imputado por regla general, no es considerada un medio probatorio dado que no es una fuente de prueba personal (puede ser fuente de prueba material), conforme a la naturaleza del hecho imputado, por ejemplo para efectos de un examen de ADN-2.

3.3.2. En el caso la declaración de la imputada solo puede ser considerada como una expresión de su resistencia u oposición, de tal manera que no constituye fuente de prueba de la pretensión penal, pero tampoco constituye prueba de la resistencia, dado que en esta última no podría considerarse como un tema de prueba y a su vez considerarse como medio de prueba $^{3}$, lo contrario llevaría a incurrir en la falacia de petición de principio "lo que afirmo es verdad porque lo he afirmado" (página 3).

No obstante, consideramos que no tiene asidero descartar el valor probatorio de la declaración del imputado si expresamente el Acuerdo Plenario $\mathrm{N}^{\circ}$ 2-2005/CJ-116, de fecha 30 de septiembre de 2005 , señala en su fundamento jurídico 8:

8. Cuando declara un coimputado sobre un hecho de otro coimputado, y que a la vez se trata de hechos propios ya que ellos mismos los han cometido conjuntamente, por lo que su condición no es asimilable a la del testigo, aún cuando es de reconocer que tal testimonio puede ser utilizado para formar la convicción judicial-no existe por ese hecho descalificación procedimental-, corresponde valorar varias circunstancias,

\footnotetext{
1 La idea de proceso supone dos partes enfrentadas respecto de un objeto; $y$, un tercero que heterocompone el conflicto.

$2 \mathrm{La}$ declaración del imputado excepcionalmente puede constituir un medio de prueba calificada como confesión; sin embargo, requiere la materialización de determinados requisitos previstos en el artículo 159 del CC3. En el caso de la terminación anticipada y la conformidad la declaración del imputado no es un medio de prueba sino una expresión de voluntad de poner fin al proceso pero sobre la base de los elementos de convicción suficientes (sospecha suficiente)

3 Quien afirma un hecho debe probarlo, pero probarlo con prueba diferente a la propia afirmación.
}

que se erigen en criterios de credibilidad -no de mera legalidad-, y que apuntan a determinar si existen datos relevantes que las desnaturalizan situaciones que explicarían que el coimputado pudiese mentir. Las cautelas que ha de tomarse en cuenta resultan del hecho que el coimputado no tiene obligación de decir la verdad, no se le toma juramento y declara sin el riesgo de ser sancionado, sin la amenaza de las penas que incriminan el falso testimonio.

Es más, el citado acuerdo plenario establece las siguientes reglas de valoración en el fundamento jurídico 9:

Las circunstancias que han de valorarse son las siguientes:

a) Desde la perspectiva subjetiva, ha de analizarse la personalidad del coimputado, en especial sus relaciones con el afectado por su testimonio. También es del caso examinar las posibles motivaciones de su delación, que éstas no sean turbias o espurias: venganza, odio, revanchismo, deseo de obtener beneficios de cualquier tipo, incluso judiciales, que por su entidad están en condiciones de restarle fuerte dosis de credibilidad. Asimismo, se tendrá del cuidado de advertir si la finalidad de la declaración no sea, a su vez, exculpatoria de la propia responsabilidad.

b) Desde la perspectiva objetiva, se requiere que el relato incriminador esté mínimamente corroborado por otras acreditaciones indiciarias en contra del sindicado que incorporen algún hecho, dato o circunstancia externa, aún de carácter periférico, que consolide su contenido incriminador.

c) Asimismo, debe observarse la coherencia y solidez del relato del coimputado; y, de ser el caso, aunque sin el carácter de una regla que no admita matizaciones, la persistencia de sus afirmaciones en el curso del proceso. El cambio de versión del coimputado no necesariamente la inhabilita para su apreciación judicial, y en la medida en que el conjunto de las declaraciones del mismo coimputado se hayan sometido a debate y análisis, el juzgador puede optar por la que considere adecuada. 
En este orden de ideas, si el citado acuerdo plenario permite la valoración probatoria de la declaración del coimputado, resulta claro que la misma tiene aptitud de generar convicción en el órgano jurisdiccional respecto a los hechos brindados en ella, careciendo de sentido lógico la idea de que únicamente es un medio de defensa y que no se puede tener en cuenta para sustentar probatoriamente la decisión jurisdiccional.

\section{CONCLUSIONES}

La lectura de las declaraciones previas del imputado durante el juzgamiento no afecta su derecho a guardar silencio si: 1) han sido llevadas a cabo con todas las garantías establecidas por la Constitución Política y el Código Procesal Penal; y, 2) luego de ser leídas se le concede al acusado la palabra para que, si lo desea, explique, aclare, refute o se pronuncie sobre su contenido.

Las declaraciones contradictorias del imputado durante el juzgamiento requieren de un tratamiento especial, el cual exige que se le pregunte al acusado por qué razón ha variado su manifestación inicial sobre los hechos para que el juez pueda percibir de manera inmediata sus explicaciones. Asimismo, el juzgador es libre de elegir cualquiera de las dos versiones, con la obligación de fundamentar de manera especial las razones por las cuales eligió esa declaración y no la otra.

La declaración del acusado tiene aptitud probatoria para ser valorada por el órgano jurisdiccional. Que la doctrina procesal mayoritaria le otorgue la calidad de medio de defensa no la excluye de tener la capacidad para generar convicción judicial sobre los hechos expuestos por el acusado en ella, y ser utilizada por el juez para sustentar probatoriamente sus decisiones.

\section{FUENTES DE INFORMACIÓN}

\section{Referencias bibliográficas}

Ferrajoli, L. (1995). Derecho y Razón, una teoría sobre el garantismo penal. Madrid, España: Editorial Trotta.

\section{Jurisprudencias}

Corte Superior de Justicia de Arequipa (2018). Pleno Jurisdiccional Distrital Penal.

Corte Suprema de Justicia de la Republica (2005). Acuerdo Plenario $\mathrm{N}^{\circ} 2-2005 / \mathrm{CJ}-116$.

Sala Penal Permanente de la Corte Suprema de Justicia de la República (2004). Recurso de Nulidad N ${ }^{\circ} 3044-2014-$ Tacna. Sentencia de 1 de diciembre de 2014.

Sala Penal Permanente de la Corte Suprema de Justicia de la República (2017), Recurso de Nulidad $N^{\circ}$ 2467-2017- Tacna. Sentencia de 18 de septiembre de 2018 .

Tercera Sala Penal de Apelaciones de la Corte Superior de Justicia de Arequipa (2017). Expediente $\mathrm{N}^{\circ}$ 92-2017, Sentencia de 5 de septiembre de 2017.

Tercera Sala Penal de Apelaciones de la Corte Superior de Justicia de Arequipa (2017). Expediente $\mathrm{N}^{\circ}$ 2324-2015, Sentencia de 5 de diciembre de 2017.

\section{Leyes}

Constitución Política del Perú de 1993.

Código Procesal Penal de 2004. 